the calıfornia Inolans

a source BOok 



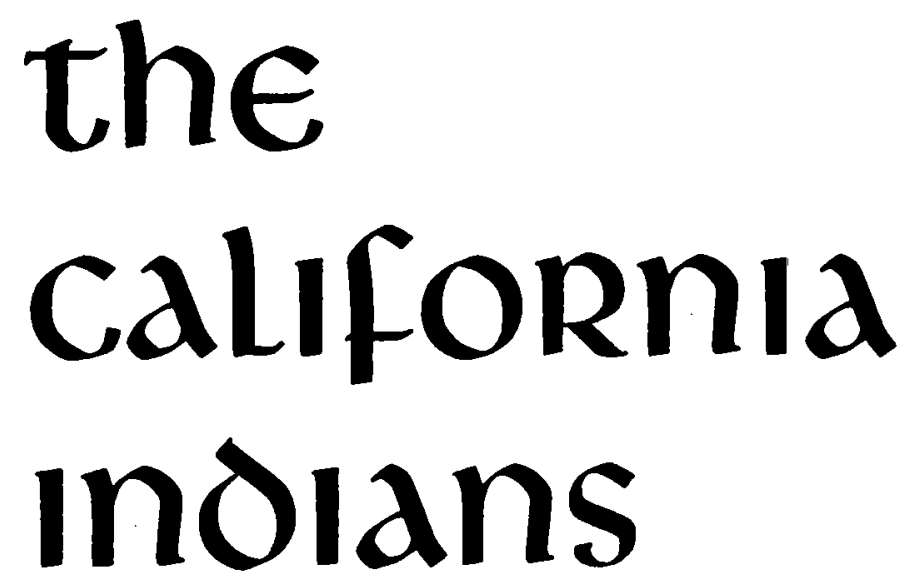

\section{a SOURCE BOOK} compileo and editeO By R. f. heizer ano m. a. Whipple

second edition revised and enlarged

university of california press Berkeley, los angeles, lonoon 
University of California Press

Berkeley and Los Angeles, California

University of California Press, Ltd.

London, England

Copyright I95 I and 197 I by the Regents of the University of California Second Edition, I971

ISBN: $0-520-01770-6$ cloth ISBN: $0-520-02031-6$ paper

Library of Congress Catalog Card Number: 72-I 2295 I

Printed in the United States of America 